\title{
Using Sport Science to Improve Coaching: A Case Study of the American Record Holder in the Women's Hammer Throw
}

lain Hunter

iain_hunter@byu.edu

Erin Gilreath

Larry W. Judge

Follow this and additional works at: https://scholarsarchive.byu.edu/facpub

Part of the Exercise Science Commons

\section{Original Publication Citation}

Judge L, Hunter I, \& Gilreath E. (28). "Using Sport Science to Improve Coaching: A Case Study of the American Record Holder in the Women's Hammer Throw", International Journal of Sports Science and Coaching, 3(4), 373-348.

\section{BYU ScholarsArchive Citation}

Hunter, Iain; Gilreath, Erin; and Judge, Larry W., "Using Sport Science to Improve Coaching: A Case Study of the American Record Holder in the Women's Hammer Throw" (2008). Faculty Publications. 909.

https://scholarsarchive.byu.edu/facpub/909 


\title{
Using Sport Science to Improve Coaching: A Case Study of the American Record Holder in the Women's Hammer Throw
}

\author{
Larry W. Judge', lain Hunter ${ }^{\mathbf{1}}$ and Erin Gilreath' \\ ${ }^{1}$ Department of Physical Education, Sport, and Exercise Science, \\ Ball State University, HP 213, Muncie, IN 47304, USA \\ Email: LWJudge@bsu.edu \\ ${ }^{2}$ Brigham Young University, Provo, UT, USA
}

\begin{abstract}
Conclusions from biomechanical data can make a significant difference in the performance of athletes in the hammer throw if properly understood by coaches. By utilizing this scientific approach to the hammer throw event, the throws coach will be able to determine more accurate adjustments and devise training stimuli to better accommodate the athlete. In this case study, we have attempted to bridge the gap between the researcher and the coach in our approach to teaching the hammer throw, by integrating biomechanical analysis. We have employed the use of video analysis as an essential part of our coaching/teaching system. This USATF Women's development hammer project is an example in which the cooperation between sport science and coaching helped to produce an American record of 73.87m by Erin Gilreath in the women's hammer in 2005.
\end{abstract}

Key words: Biomechanics, Field Athletics Coaching, Throwing Technique, Video Feedback

\section{INTRODUCTION}

All sport movements are a combination of technique and athleticism. As a coach, developing programs to emphasize both is the key to successful performance. The track and field event known as the hammer throw requires a vast amount of technical expertise. Combining strength, balance, timing, and the necessity of near-perfect technique, the hammer throw is one of the most exciting and artistic of the field events.

In recent years, competition in the women's hammer throw has developed to such a high level that no athlete or coach can afford to neglect the application of scientific principles to the event. By utilizing this critical scientific approach to the hammer throw event, the throws coach will be able to determine more accurate adjustments and devise training stimuli to facilitate improved and successful performances. Objective data on the hammer throw can be quantified, measured and studied by researchers and trained coaches who have had the opportunity to prepare themselves in the study of human motion. James Hay, in his book, The Biomechanics of Sports Techniques, defined biomechanics as "the science that examines the internal and external forces acting on a human body and the effects produced by these forces" [1]. 
It is surprising what incredible interest and self-assurance can be developed in your athletes relating the branch of physics called mechanics to the presentation of fundamental techniques of hammer throwing. Proof based on the evidence of the immutable laws of physics is both compelling and motivating to athletes. Unless there is a through understanding of hammer biomechanics, the thrower may be limited in his or her progression. A flaw in the hammer thrower's technical approach cannot be considered corrected until that athlete can clearly identify and understand the cause of the faulty execution.

Conclusions from biomechanical research can make a significant difference in the performance of athletes in the hammer throw if properly understood by coaches. The type of observations and or conclusions that can be made from a segment of video on a particular athlete depends on a number of factors related to the type of video, the way in which the video was shot, and the skills of the videographer and researcher. Further, any individual throw by an athlete could be unique and atypical. The coach and researcher must work together to improve technique in the hammer throw.

This article will describe the USATF Women's development hammer project in which the cooperation between sports science and coaching helped to produce an American record (AR) of $73.87 \mathrm{~m}$ by Erin Gilreath in the women's hammer in 2005. This research conducted a biomechanical analysis of American hammer thrower Erin Gilreath at the 2003, 2004 and 2005 United States Track and Field nationals (Figure 1). The methodology and procedures will be presented as a guide for other coaches or researchers desiring to analyze the technique of their athletes using video analysis.

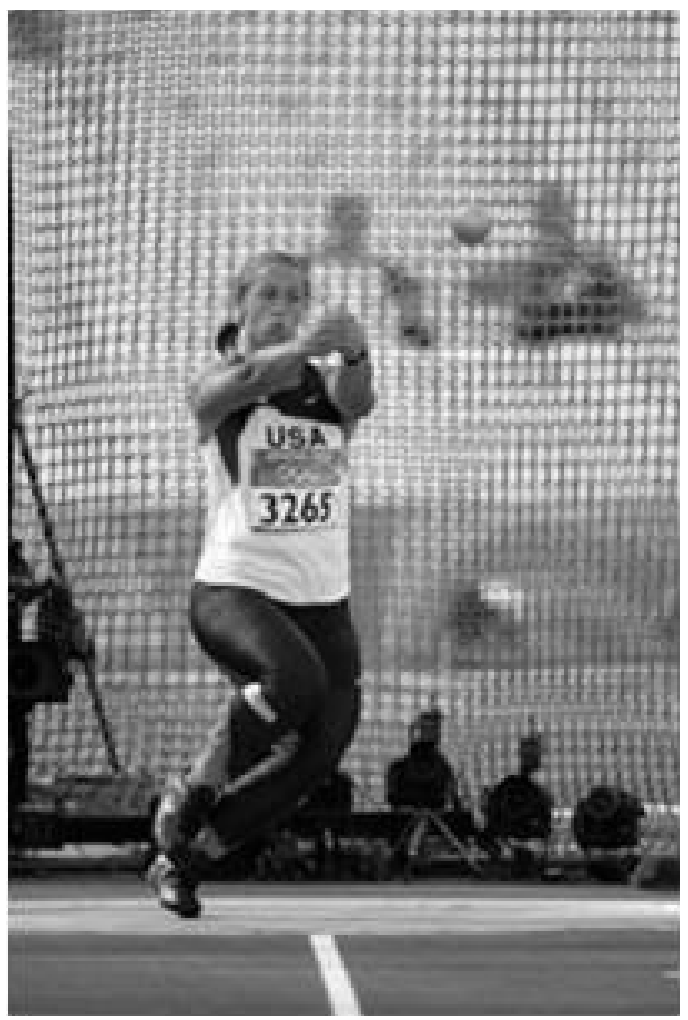

Figure 1. Erin Gilreath at the Athens Olympic Games in 2004 


\section{METHODS}

Two digital video cameras (Canon Elura 60) running at $60 \mathrm{~Hz}$ were placed to view Erin Gilreath's (Tables 1 and 2) best throws at the 2003 USATF Nationals (64.83 m), 2004 Olympic Trials (70.42 m), and 2005 USATF Nationals (73.87 m, American Record). One camera was placed perpendicular to the throwing direction to obtain the release angle. Release velocity was calculated according to the explanation by Hunter [2]. The other camera was placed behind the athlete to determine the length of time in single and double support phases (during each turn of the hammer throw some time is spent with both feet on the ground, double support; and some time spent is with only one foot on the ground, single support. The Dartfish ProSuite 4.0 was used to measure release angle, height, and support phase duration. Following each of the competitions in 2003 and 2004, the coach sat down with the sport scientist and reviewed each of the throws. A few weeks later a detailed biomechanical analysis was sent to the coach.

Table 1. Testing Data

Personal Information

Height: $177 \mathrm{~cm}$ Weight: $95 \mathrm{~kg}$

\begin{tabular}{cccccccc} 
Year & $\begin{array}{c}\text { Body } \\
\text { Mass } \\
(\mathbf{k g})\end{array}$ & $\begin{array}{c}\text { Body } \\
\text { Fat Percent } \\
(\boldsymbol{\%})\end{array}$ & $\begin{array}{c}\text { Overhead } \\
\text { Back Shot } \\
\text { Put }(\mathbf{m})\end{array}$ & $\begin{array}{c}\text { Power } \\
\text { Clean } \\
(\mathbf{k g})\end{array}$ & $\begin{array}{c}\text { Power } \\
\text { Snatch } \\
(\mathbf{k g})\end{array}$ & $\begin{array}{c}\text { Squat } \\
(\mathbf{k g})\end{array}$ & $\begin{array}{c}\text { Bench } \\
\text { Press } \\
(\mathbf{k g})\end{array}$ \\
\hline 2005 & 95 & 18.1 & 17.60 & 115 & 85 & 205 & 95 \\
\hline 2004 & 92 & 15.5 & 17.80 & 110 & 80 & 185 & 90 \\
\hline 2003 & 102 & 23.2 & 17.02 & 105 & 75 & 175 & 88.5 \\
\hline
\end{tabular}

Table 2. Progression and Finish at Major Championships

\begin{tabular}{lcccccc} 
Year & $\begin{array}{c}\text { Shot } \\
\text { Put }(\mathbf{m})\end{array}$ & $\begin{array}{c}\text { Weight } \\
\text { Throw } \\
(\mathbf{m})\end{array}$ & $\begin{array}{c}\text { Domestic } \\
\text { Indoor } \\
\text { Competitions }\end{array}$ & $\begin{array}{c}\text { Hammer } \\
\text { Throw } \\
(\mathbf{m})\end{array}$ & $\begin{array}{c}\text { Domestic } \\
\text { Outdoor } \\
\text { Competitions }\end{array}$ & $\begin{array}{c}\text { International } \\
\text { Competitions }\end{array}$ \\
\hline 2005 & N/A & $24.46^{*}$ & $1^{\text {st }}$ USATF & $73.87^{\wedge}$ & $1^{\text {st }}$ USATF & $10^{\text {th }}$ WC \\
\hline 2004 & N/A & $23.95^{*}$ & 1 st USATF & $72.12^{\wedge}$ & $1^{\text {st }}$ USATF & $16^{\text {th }}$ OG \\
& & & & & $8^{\text {th }}$ WAF \\
\hline 2003 & 16.07 & $22.02^{\#}$ & $1^{\text {st }}$ NCAA & 64.83 & $4^{\text {th }}$ USATF & DNQ \\
\hline 2002 & 15.90 & 18.90 & DNQ & 57.33 & $16^{\text {th }}$ USATF & \\
\hline 2001 & Did & Not & Compete & & & \\
\hline 2000 & Did & Not & Compete & & & \\
1999 & Did & Not & Compete & & & \\
\hline 1998 & 11.61 & N/A & N/A & N/A & N/A & \\
* World Record & \multicolumn{7}{l}{} \\
A American Record \\
\# NCAA Meet Record
\end{tabular}




\section{TRAINING PROGRAM}

The definitive goal of training throwers, in the authors' opinion, is the functional reconstruction of the athlete, resulting in enduring adaptation and preservation of the training effect. When considering the variables that make up the training program (i.e., training load, training volume, exercise selection, and training frequency) how much of each in a quality training plan could depend upon the athlete's training age, his or her strengths and weaknesses, the phase of the training year, as well as many other factors. For a hammer thrower, there must be a balancing of the training loads with restorative and prophylactic measures.

A classic Matveyev periodization model was utilized because of Erin's young training age [3]. The mesocycle sequencing of the training program begins with hypertrophy methods, progressing into strength building methods, followed by neural activation methods, and finally speed-strength methods. The total cycle is repeated three times annually. For example, the first mesocycle emphasizes strength-endurance, basic conditioning and hypertrophy methods (up to 8 weeks is permissible if the athlete requires muscle mass) (midAugust - early September.) The second mesocycle emphasizes basic strength with an emphasis on improving the squat (late September - early October) The third mesocycle emphasizes strength/power using 3-4 weeks of neural activation methods with the emphasis on Olympic lifts and Olympic lifting derivatives and plyometrics (late October - early November). The fourth emphasizes explosive power and speed development using time controlled speed-strength methods (late November - early December). The sequence would then repeat following a regeneration period (December holiday).

Olympic-style lifts (clean, jerk, and snatch) and their derivatives (pulls and shrugs) are the core of the resistance training program. Numerous studies and review articles have reported evidence and logical arguments for the use of explosive exercises for hammer throwers. In addition to the weight lifting exercises, throws, sprint drills and jumps; the workout contains sport-specific release movements that force core stabilization of high-velocity activities. Sport-specific exercises that mirror sport specific release parameters are an effective way to special strength. Heavy weights (20 or $25 \mathrm{lb}$ ) are used for power and lighter weights for speed. These exercises are designed to emulate key sport-specific release positions.

Following the 2003 season, the volume of throws was drastically increased due to the relatively young training age of the athlete and to make up for the lack of experience with the hammer. With the Olympic year quickly approaching, increasing the demand of training was determined as the best way to secure a berth on the US Olympic team for Erin. The number of total throws increased from 5440 in 2003 to 8096 in 2004 (Table 3). Keep in mind that these numbers include everything that was done with a delivery. This includes full throws, drills with a release, and one and two turns throw with a release. Of the 5440 total throws in 2003, 2340 were performed with the weight and 3100 were performed with the hammer. In 2004, 3528 throws were performed with the weight and 4568 throws were performed with the hammer. Throws were completed with hammers ranging from $3.5 \mathrm{~kg}$ to $6 \mathrm{~kg}$. Throws were completed in the weight with implements ranging from $9 \mathrm{~kg}$ to $14.5 \mathrm{~kg}$. The majority of the weight throws were performed in the fall and winter months and the majority of the hammer throws were performed in the spring and summer months. During the preparation, and pre-competitive phase, three throwing workouts were performed daily. This was reduced to two workouts a day during the competitive phase. Two training days were generally followed by one recovery day. 
Table 3. Throwing Volume (Number of Throws Per Year).

\begin{tabular}{cccc} 
Year & Weight Throws & Hammer Throws & Total \\
\hline 2005 & 2808 & 3944 & 6752 \\
\hline 2004 & 3528 & 4568 & 8096 \\
\hline 2003 & 2340 & 3100 & 5440 \\
\hline
\end{tabular}

Following the 2004 season, the number of throws in training was reduced. In 2005, 2808 throws were performed with the weight and 3944 throws were performed with the hammer for a total of 6752. During the preparation, and pre-competitive phase, two throwing workouts were performed daily. This stayed the same during the competitive phase. Two training days were generally followed by one recovery day. Throws were completed with hammers ranging from $3.5 \mathrm{~kg}$ to $7.26 \mathrm{~kg}$. Throws were completed in the weight with implements ranging from $9 \mathrm{~kg}$ to $16 \mathrm{~kg}$. During this year the emphasis was on improving maximum strength in the lower body.

\section{RESULTS}

Release angles were nearly equal between all throws. However, release velocity increased with throw distance (Table 4). The American record throw had a release velocity of $27.2 \mathrm{~m} / \mathrm{s}$. No trends were observed in support phase times (Tables 5a-c). However, the 2003 throw showed a relatively longer total time in turns two and three.

Table 4. Release Angle and Velocity of Each Throw at the US Championships.

\begin{tabular}{ccc} 
Year and Throw Distance & Release Angle $(\mathbf{d e g})$ & Release Velocity $(\mathbf{m} / \mathbf{s})$ \\
\hline $2005(73.87 \mathrm{~m})$ & 41 & 27.2 \\
\hline $2004(70.42 \mathrm{~m})$ & 43 & 26.5 \\
\hline $2003(64.83 \mathrm{~m})$ & 42 & 25.9 \\
\hline
\end{tabular}

Table 5a. Temporal Phases of the 2005 (73.87 m) throw.

Time (s)

\begin{tabular}{cccccc}
\hline & Turn 1 & & & Turn 2 & \\
\hline Single & Double & & Single & Double & \\
Support & Support & Ratio & Support & Support & Ratio \\
\hline 0.32 & 0.43 & $42.7 \%$ & 0.27 & 0.28 & $49.1 \%$ \\
\hline & Turn 3 & & & Turn 4 & \\
\hline Single & Double & & Single & Double & \\
Support & Support & Ratio & Support & Support & Ratio \\
\hline 0.23 & 0.23 & $50.0 \%$ & 0.25 & 0.23 & $52.1 \%$ \\
\hline
\end{tabular}


Table 5b. Temporal Phases of the 2004 (70.42 m) Throw.

Time (s)

\begin{tabular}{cccccc}
\hline & Turn 1 & & & Turn 2 & \\
\hline Single & Double & & Single & Double & \\
Support & Support & Ratio & Support & Support & Ratio \\
\hline 0.35 & 0.55 & $38.9 \%$ & 0.25 & 0.35 & $41.7 \%$ \\
\hline & Turn 3 & & & Turn 4 & \\
\hline Single & Double & & Single & Double & \\
Support & Support & Ratio & Support & Support & Ratio \\
\hline 0.23 & 0.20 & $53.5 \%$ & 0.28 & 0.22 & $56.0 \%$ \\
\hline
\end{tabular}

Table 5c. Temporal Phases of the 2003 (64.83 m) Throw.

Time (s)

\begin{tabular}{cccccc}
\hline & Turn 1 & & & Turn 2 & \\
\hline Single & Double & & Single & Double & \\
Support & Support & Ratio & Support & Support & Ratio \\
\hline 0.32 & 0.42 & $43.2 \%$ & 0.32 & 0.30 & $51.6 \%$ \\
\hline & Turn 3 & & & Turn 4 & \\
\hline Single & Double & & Single & Double & \\
Support & Support & Ratio & Support & Support & Ratio \\
\hline 0.25 & 0.27 & $48.1 \%$ & 0.25 & 0.23 & $52.1 \%$ \\
\hline
\end{tabular}

\section{DISCUSSION}

Various biomechanical characteristics of the hammer throw distinguish American record holder Erin Gilreath from other hammer throwers. At a height of $177 \mathrm{~cm}$, weight of $95 \mathrm{~kg}$ and body fat of $18.1 \%$, Erin does not possess great physical attributes as compared to other female hammer throwers. Yet, she has recorded the best hammer throw all-time by an American female. This success is due to an efficient technical pattern and a balanced approach to training.

\section{THE ENTRY}

One of the biggest challenges with Erin was working on her entry. In her second year throwing, 2003, Erin was not very comfortable with her winds and entry. The winds, one of the most important technical elements of the hammer throw, are responsible for the throwing rhythm and tempo, the position of the lowest point in the rotational trajectory of the hammer, the movement of the hammer head into an optimal position and the placement of the athlete's body into a suitable position for the turns to follow. The stability in the execution of the preliminary swings is so important that, in a methodical development, this element should be completed before the throwing action as a whole begins. She had difficultly staying relaxed with her arms on the winds and she appeared to be off-balance. Her winds impacted her balance on her start which tended to slow her down on turns two and three. One of the differences from 2003 to 2005 was the consistency of the start. One of the adjustments made was to widen her initial starting position. The suggested placement of the feet is wide $(70 \mathrm{~cm}$ to $80 \mathrm{~cm}$ ) to create a maximal rotational momentum [4]. Changes to this position, by even $2 \mathrm{~cm}$, influence the subsequent structure of the throw. The wider base of $(75 \mathrm{~cm})$ allowed 
Erin to be more balanced and stable in her starting position. The objective on the start was to achieve a flat orbit on the entry turn. This flat orbit allowed Erin to be on balance as she transitions from the toe turn to the heel turn. Most throwers obtain a steeper orbit earlier in the throw. Because of the adjustment, Erin could stay more controlled by making a more gradual progression to increase the orbit. However, she still achieves higher than a $40^{\circ}$ release angle, which is ideal.

The position of the low point following the winds can have a profound impact on the mechanics of the throw. In 2003, Erin set up her low point a little right of center. Positioning of the low point of the trajectory a little to the right of the center line makes it easier to accelerate the implement in the first turn, but at the same time makes it harder to produce a wide hammer arc movement to the left. As Erin became more technically proficient in 2004 and 2005, the low point was set up at $0^{\circ}$. We felt that athletes with a high level of speed capacities and in complete control of the technique have no need to "advance" the low trajectory point by 40 to $45^{\circ}$ to the right, but can place the hammer head straight in front of themselves already in the first turn.

Erin maintained a fairly upright starting position in 2003, 2004 and 2005. In 2005, we started working on a slight forward lean of the trunk on the entry. A slight forward lean of the trunk, in the double-support phase, allows the thrower to maintain balance when the angular velocity of his/her body is reduced and the absolute velocity of the implement is relatively high. This is one of the main advantages of the four-turn technique, as it makes it possible to start slower and allows for a smoother change of kinematic indicators. The rotational radius is reduced as the trunk straightens and the angular velocity is consequently increased. Erin was fairly comfortable with the upright position in the start, but was able to add a modest lean in 2005. The challenge with Erin was to get her to transition from the slight forward lean of the toe turn to the more upright posture of the second heel turn. Because Erin is inexperienced and a weaker athlete, this would certainly inhibit control of the left side and make the transition into the next turn a challenge. This was one of the technical factors to be emphasized in 2006.

\section{THE TURNS}

The turning rhythm is established in the transfer from the preliminary swings into the first turn. Another important element in hammer throw technique that we worked on is the lifting or removal of the right foot from support. One of the challenges for Erin was to obtain early right foot placement. To achieve this, we worked on lifting the right leg earlier each turn. The emphasis was on pushing the right side until the right foot comes off the ground. According to contemporary views, this should take place when the thrower's body is at a $90^{\circ}$ angle from the frontal plane in the first turn [5]. This permits the lengthening of the double support phase in relation to the single support. As the velocity of the turns increases, most throwers begin to lift the right leg earlier and earlier in each turn. According to Petrov, the angle is reduced to $80^{\circ}$ in the second turn and $75^{\circ}$ in the third [6]. Erin was taught to think about driving the right side so the right leg lift-off happens naturally. In theory, the right leg loses contact with the surface when the angular velocities of the hammer and the athlete's body are equal and continues until the implement passes its highest point. The right leg moves in the singlesupport phase within a minimal radius to secure a fast foot placement [7].

\section{ACCELERATING THE BALL}

This area of technique was based on the "Russian Model" [8]. The acceleration of the hammer is produced by the build-up and unwinding of the torque between the feet and the 
hip axis. From the right foot touch-down, the hammer is accelerated to $0^{\circ}$ (although it was emphasized to keep pushing the right side until right foot lift-off). The concept of optimizing the degrees of acceleration during each turn and overall during the throw was the emphasis. We worked on achieving approximately 40 to $60^{\circ}$ of separation during each catch phase. This was a modest amount of separation, in favor of a more stable body position. When more separation was achieved, Erin had a tendency to drag the hammer. Angles of separation in the hammer throw have been discussed in coaching literature, but not highly researched [9]. The angle of separation between the shoulders and the hammer is the angle formed between the shoulders as it intersects with an imaginary line from the hammer head. The shoulder/hip separation in the catch phase creates torque that accelerates the hammer and is the key to the subject's success. Proper torque application will add to the angular momentum needed to increase throwing distance. A smooth acceleration pattern was a big point of emphasis with Erin. The emphasis was placed on accelerating the ball by getting into the correct positions during throw. Because Erin lacks strength and size, she uses her hips to create force by accelerating the hammer. Utilizing the larger muscles of the lower body has enabled Erin to beat competitors who are much bigger and stronger. Optimizing this position was a point of emphasis with Erin, but too much emphasis on this technical point makes it difficult to hookup with the hammer at $0^{\circ}$.

A characteristic which differentiates Erin from other hammer throwers is the countering of the hammer (Figure 2). In many cases, throwers project forward slightly at the waist to increase the radius of the hammer in the early turns by countering with the hips; and on turns three and four, they will counter with the shoulders resulting in a disadvantageous hammer radius [10]. The radius shortens when the centripetal forces are great enough that the upper body needs to work to help counter the hammer [11]. The position of the head really allowed Erin to counter the hammer with her lower body and maintain a long radius. In 2003, she sometimes looked ahead of the ball. Turning the head to the left of the implement led to bending of the right arm, reduced the radius of the rotation, affected balance, and also led to straightening of the left leg. One of the technical aspects that we worked on with Erin was improving her counter to increase her speed in the later turns. The radius decreases in turn 4 and release in the AR throw. This is not typical, especially to this extreme. In the AR throw in 2005, Erin is building up angular momentum during turns 1-3, and then increases the angular and linear velocity of the hammer by decreasing the radius earlier than most. The position of the head during the turns was an area that we gave a considerable amount of attention. It is generally accepted that looking straight ahead and slightly upwards helps to maintain the trunk on the rotational axis. This point was worked during the drill sessions and eventually became a stable part of her throw.

We worked on smoothing out Erin's acceleration pattern. Because she was relatively new to the event, we emphasized a slower start with solid positions and a gradual acceleration. The gradual acceleration should not increase velocity more than approximately $25 \%$ in each subsequent turn [5]. Highly qualified throwers stand out with their smooth acceleration of the hammer in the double support phases and a gradual shortening of the single support phases, which are shorter than the corresponding double support phases. Increasing time in DS and shortening SS is a technical challenge that Erin can continue to work on. 


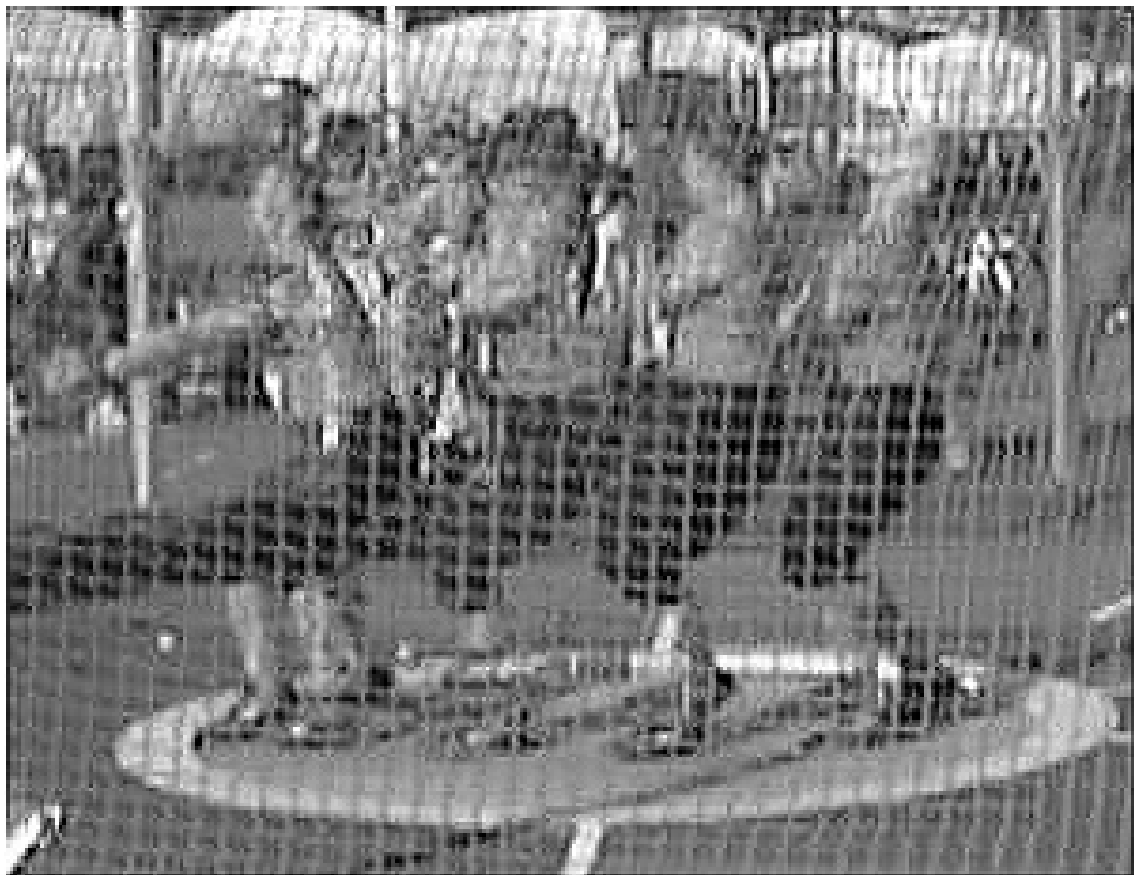

Figure 2. Countering Positions of Each of the Four Turns During Double Support

\section{FINAL DELIVERY}

An effective delivery and a long throw is possible even after certain technical shortcomings in the earlier stages of the throw, provided the athlete reaches a maximal possible turning velocity and has an effective delivery position with a near-vertical trunk, closely placed feet and a rotational plane of the implement around $40-45^{\circ}$.

The large difference between throw distances from 2003 to 2005 is mainly due to increased release velocity. Since support phase times showed little information in helping predict throw distance, other mechanical factors must have contributed to increased performance. The 2003 throw having longer times in turns two and three indicates a slower rotational speed. The filming in this project did not allow us to measure radius with reasonable accuracy. However, the timing of double and single support shows that a greater radius likely occurred since the hammer was going further. The velocity of the hammer head can be calculated by multiplying the angular velocity by the radius from the axis of rotation to the center of mass of the hammer. Realizing that the hammer was going faster and the rotation was slower in the further throws, an increased radius is the only factor left that could have increased speed.

The final delivery action should take place without a significant backward lean of the trunk (Figure 3). The legs begin to straighten when the implement passes the low point of its trajectory. The release of the implement occurs when the implement is placed at the level of the athlete's shoulders. A balanced position after the release reflects properly executed delivery movements. The biggest difference between Erin's release in 2003 and 2004 and the AR throw in 2005 was the balance at release. This was something we emphasized in training. 
Many throws with puds, weights and plates were performed with the emphasis on proper alignment. Many hammer throwers use primarily the musculature in the shoulder and arms to generate force. As evidenced by the joint angles in the catch position, the subject's hips are in a fairly low position and there is separation between the shoulders and hips, although the upper body is erect.

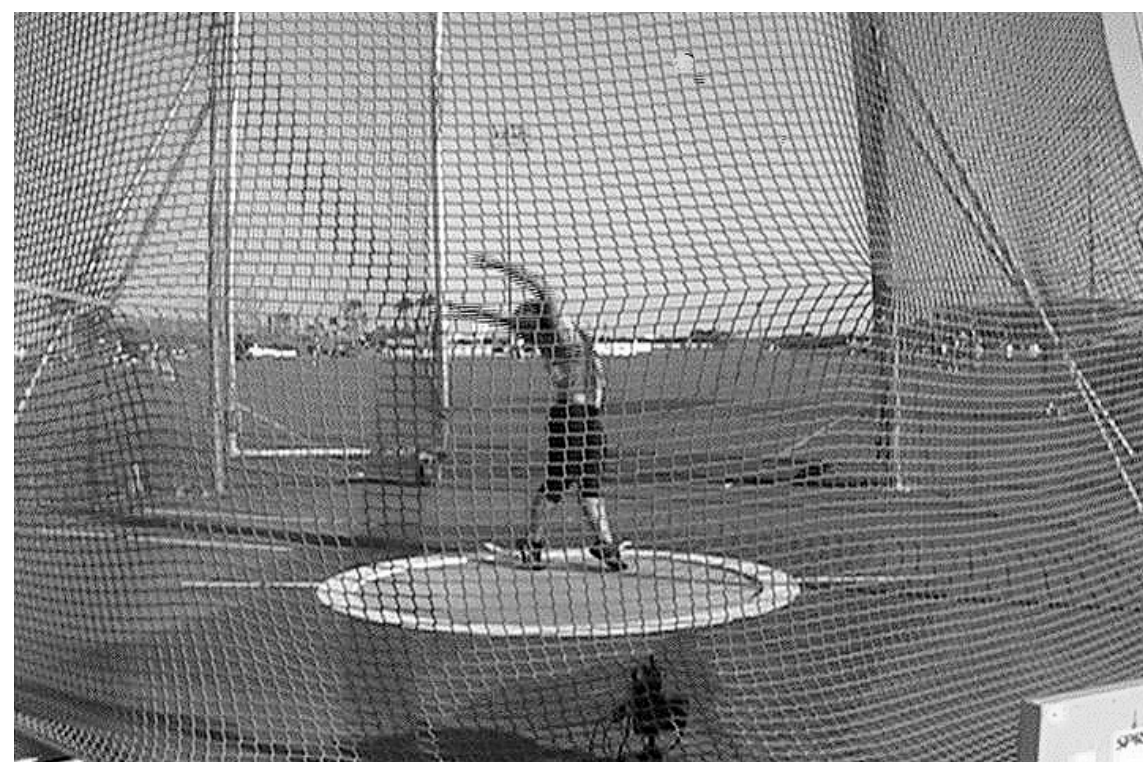

Figure 3. Following the Release, the Athlete Should Be in an Upright Stable Position.

Erin has a very forceful rotary motion in the push-off phase of the throw, but because of a lack of strength, the subject had trouble maintaining the velocity through the release in 2003. A technical adjustment in this area could bring improvement. The lack of blocking force of the left leg was a possible limiting factor in achieving release velocity. The stopping force of the front leg contributes to the transfer of force to the hammer. In 2004 and 2005, Erin makes up for deficiencies in strength and size with a sound technical pattern that sets up the final turn and release thus creating the velocity necessary to move the implement.

During meetings between the USATF biomechanist, coach and athete, improvements in technique focused on increasing velocity of the hammer head. Angular momentum can be built up during the double-support phase (when both feet are on the ground) $[12,13]$. As angular momentum is increased, linear velocity of the hammer head will also increase. Greater increases in angular momentum can be found when engaging trunk rotation along with the torque generated by ground reaction forces [11]. Therefore, focus was put on rotating the lower body around quickly during single-support to have the line through the hip joints lead the line through the shoulder joints. Then during double-support, the trunk should rotate back to a neutral position. In these meetings, the biomechanist, coach and athlete determined that good positions were being accomplished and the main focus should be upon improving velocity through conditioning rather than technique modifications. 


\section{RECOMMENDATIONS}

This case study will attempt to offer guidance to coaches as a background for the analysis of the technique and the planning of the training load. In the hammer throw, there exists an inseparable relationship between technique and performance; the perfection of technique has to be a year-round task [4]. Tremendous interest and confidence can be developed in your athletes by relating biomechanical principles to the presentation of fundamental techniques of hammer throwing. Proof based on the evidence of the laws of physics is both convincing and motivating to athletes. The everlasting development of the understanding of the basic elements of the hammer throw technique (the correct internal image of the technique) is a must for both coaches and athletes [4]. By adopting the above procedure in the selection and development of fundamental skills in the hammer throw, one can have confidence in the soundness in his or her conclusions.

Athletes and coaches alike are always looking for that magical formula for success; the only way to achieve success in the hammer is by following a consistent training regime that incorporates a system of technical development, overload, progressive resistance and recovery. The coach can help improve weight room strength, but lifting needs to be specific. There is no time to do resistance training, such as bench press, or other training that is not related to throwing the hammer. Lifts emphasized should be the squat, and the Olympic lifts. In addition to working hard in the weight room, throws and drills with heavy implements to build "specific throwing strength" are part of the regime. Improvements in throwing and general strength will make it possible for the coach to engineer technical advancements. Closer to the season, more work with lighter implements to build speed, and refine the timing of the technical model is added to the training program. However, the specific movement pattern of throws with implements of different masses and lengths does not automatically cause the essential changes required for enhancement of the competition throws. The projected changes happen only after consideration of the technique of throws with special implements [4].

America's best female hammer thrower, Erin Gilreath, demonstrates a high level of athletic technique. She is currently one of the top female hammer throwers in the world. However, despite all the positive elements shown, the analysis shows that there is room for further improvement. To challenge the current world record of $(78.61 \mathrm{~m})$, Erin must continue to develop some key areas physically and technically. Erin must improve overall explosive strength in order to be able to make improvements in hammer head velocity while continuing to focus on the following aspects of technique:

1. Proper body positions in the start; let the ball get ahead at $0^{\circ}$

2. Early right foot placement in the later turns

3. Shorter time in DS vs. SS

4. Optimum shoulder-hip separation in the later turns

\section{CONCLUSION}

As a coach, you must attack the athlete's main areas of weakness. Each athlete will differ in natural talent and physical characteristics, therefore the coach must choose a model that best fits each athlete. Objective data on the hammer throw can be quantified, measured and studied by researchers and trained coaches. This data can be used to determine the effect of each body segment to the total action. The coach must work with a biomechanist to suggest mechanical changes to improve athletic performance. In this case study, we have attempted to bridge the gap between the researcher and the coach in our approach to teaching the hammer throw, by integrating biomechanical analysis. We have engaged the use of video 
analysis along with the use of photo sequences as an essential part of our coaching/teaching system. This USATF Women's development hammer project, in which the cooperation between sports science and coaching, helped to produce an American record of (73.87 m) by Erin Gilreath in the women's hammer in 2005.

\section{ACKNOWLEDGEMENT}

Thank you to USA Track and Field for their monetary support of this study.

\section{REFERENCES}

1. Hay, J. G., The Biomechanics of Sports Techniques, Prentice Hall, Upper Saddle River, NJ, 1993.

2. Hunter, I., The Effect of Venue and Wind on the Distance of a Hammer Throw, Research Quarterly in Exercise and Sport, 2005, 76(3), 347-351.

3. Matveyev, L. P. and Gijatsova, V.B., The Dynamics of the Training Load, Modern Athlete and Coach, 1991, 29(4), 16-19.

4. Bartonietz, K., Barclay, L. and Gathercole, D. (1997). Characteristics of Top Performances in the Women's Hammer Throw: Basics and Technique of the World's Best Athletes, New Studies in Athletics, 1997, 12, 101109.

5. Romanov, I., Women and the Hammer: Some Technical and Kinematic Characteristics, Modern Athlete and Coach, 1988, Oct (36), 35-37.

6. Petrov, V., Hammer Throw Technique and Drills, Translated Excerpts from Legkaja Atletika, Moscow (1980), \#8.

7. Payne, H., The Mechanics of Hammer Science, Athletics Science Bulletin, 1992, 4(1).

8. Bondarchuk, A. P., The Technique of the Hammer Throw, in: Homenkov, L.S., ed., A Trainer's Manual for Track and Field, Moscow, 1982, 421-437.

9. Otto, R., NSA Photosequence 22 - Hammer Throw:' Yuriy Sedykh 86.74w, Commentary, New Studies in Athletics, 1992, 7(3), 51-65.

10. Dapena, J., A Kinematic Study of Center of Mass Motions in the Hammer Throw, Journal of Biomechanics,1986, 19(2), 147-158.

11. Dapena, J. and McDonald, C., A Three-Dimensional Analysis of Angular Momentum in the Hammer Throw, Medicine and Science in Sports and Exercise, 1989, 21, 393 206-220.

12. Kollody, O., The Training of Juniors in the Hammer Throw, Track and Field, 1975, 12, 14-15.

13. Bosen, M., A Comparison in the Duration of Acceleration of the Hammer Path in the Single and Double Support Phases, Snipes Journal, 1980, 3-11. 